\title{
Identifying and challenging unhelpful thinking
}

\author{
Chris Williams \& Anne Garland
}

This is the third in a series of papers that address how to offer practical cognitive-behavioural therapy (CBT) interventions within everyday clinical settings. The first two papers (Williams E Garland, 2002; Wright et al, 2002) describe the Five Areas Assessment model and its application. The final two (Garland et al, 2002; Whitfield $\mathcal{E}$ Williams, 2002) will cover overcoming problems of altered behaviour (reduced activity and avoidance) and summarise the evidence base for the effectiveness of CBT.

In the first two articles of this series (Williams \& Garland, 2002; Wright et al, 2002), we looked at the different areas of human experience that alter during times of mental illness. The Five Areas Assessment model (Williams, 2001; see also Fig. 1 of Williams \& Garland, 2002) provides a clear summary of the range of problems and difficulties faced by the individual in each of the following domains:

1 life situation, relationships, practical problems

2 altered thinking

3 altered emotions (moods or feelings)

4 altered physical feelings/symptoms

5 altered behaviour or activity levels.

The Five Areas model shows that what individuals think about a situation or problem may affect how they feel emotionally and physically and also alter what they do. The five areas are interdependent, each exerting an influence over the others.

This article is based on material contained in Structured Psychosocial InteRventions In Teams: SPIRIT Trainers' Manual. Further details available from the author upon request.

\section{Altered thinking in different mental disorders}

Experimental research data (e.g. Williams \& Dritschel, 1988; Dalgleish \& Watts, 1990) have confirmed that both the processing styles and the content of thinking vary in different emotional states.

\section{Characteristic changes in thinking in depression}

Patients with depresssion are more negative about things when compared with other clinical groups and controls (Hagga et al, 1991). Beck et al's (1979) model proposes the negative cognitive triad, with a negative view of self, the world and the future - this model is also supported by research evidence (Blackburn \& Eunson, 1989). In addition, patients with depression have impaired problem-solving skills (Nezu et al, 1989). Furthermore, they take longer to retrieve positive memories and are more readily able to access negative memories (Clark \& Teasdale, 1982). This might explain the common clinical situation when such patients tell you that they have 'done nothing' over recent weeks, despite evidence to the contrary - they are simply remembering the negative and overlooking the things that they have achieved. These thoughts lead to altered behaviour such as reduced activity or unhelpful behaviours (Fox et al, 2002).

Chris Williams, a senior lecturer in psychiatry (Department of Psychological Medicine, Academic Centre, Gartnavel Royal Hospital, 1055 Great Western Road, Glasgow G12 0XH, UK) is President of the British Association for Behavioural and Cognitive Psychotherapies (BABCP) and a member of the Royal College of Psychiatrists' Psychotherapy Faculty Executive. His main interest is in the role of depression as a predictor of outcome in patients with medical illness. Anne Garland, a nurse consultant in psychological therapies (Regional Psychotherapy Unit, St Ann's House, London) is a member of the Accreditation and Registration Sub-Committee of BABCP and a well-known CBT trainer and researcher. 


\section{Characteristic changes in thinking in anxiety disorders}

In contrast to the negative content of thought in depression, for patients with anxiety disorders (panic disorder, agoraphobia, generalised anxiety and phobic disorders) common thinking themes are an increased perception of danger and threat combined with a decreased perception of their own ability to cope with that danger. Typical thoughts and images include themes of vulnerability, loss of control, fear of social ridicule, physical harm and death (Beck \& Emery, 1985). In terms of how information is processed, anxious patients are more prone to scan for potential threats than are controls and they have lower thresholds for noticing potential threats (Mathews \& MacLeod, 1986). The result is the avoidance of anxiety-provoking situations, or the start of unhelpful behaviours such as reassurance-seeking, drinking to excess or misusing sedative medication (Fox et al, 2002).

\section{Characteristic thinking associated with anger}

Beck (1976) suggests that the content of thoughts associated with anger is derived from a perception that someone else has broken an individual's idiosyncratic rules of what is fair and just, or acts to threaten or frustrate the individual in some way. Typical thoughts include 'shouldn' $t^{\prime}$ or 'mustn' $t$ ' statements ('She shouldn't say that to me!'), or taking things personally ('He is doing that on purpose'). The individual may jump to the conclusion that the other person is completely bad ('He's a total git') and this leads to actions such as making critical comments or attacking the other person, either actively or passively.

\section{Characteristic thinking associated with guilt}

The content of thoughts associated with guilt is derived from a perception that the individual has broken his or her own idiosyncratic rules of what is fair and just. Typical examples include statements such as 'I should have done that' or self-critical thoughts such as 'It's my fault' and frequently involve themes of excessive responsibility-taking and underlying rules to put duty before all else (Beck, 1976). Individuals may judge themselves to be totally bad and overlook their strengths. They may act in ways that confirm this by setting themselves up to fail or taking part in self-punishing behaviours such as deliberate self-harm.

\section{Characteristic thinking associated with shame}

The content of thoughts associated with shame is derived from individuals' perceptions that they have undesirable qualities (e.g. physical appearance, emotions, personality traits) or behaviours/actions which, if revealed to others, will result in ridicule and humiliation. The thought that they are total failures and that others see them in this way drives their behaviours, which aim to hide these undesirable qualities (Gilbert, 1998).

\section{Finding a language for altered thinking}

The traditional language of cognitive-behavioural therapy (CBT) describes the thoughts summarised above as negative automatic thoughts, which show a range of thinking errors or cognitive distortions. In developing the Five Areas model, the language used was extensively tested by a range of health care practitioners who used the approach with their patients (Williams \& Whitfield, 2001). It was found that the concept of negative automatic thoughts failed to use an easily accessible language and required quite a lot of explaining to patients. It was also reported that the term 'thinking error' led to misunderstanding in some patients with depression, who concluded not only that they were depressed, but also that they were thinking wrongly. As a result, the Five Areas model instead uses the term 'extreme and unhelpful thoughts'. These are thoughts that show one of the unhelpful thinking styles. This can be defined either in terms of the content of thoughts or the way in which information is processed (e.g. focusing on the negative aspects of a situation or an increased likelihood of perceiving danger in situations that are quite safe). The goal of treatment is therefore to help individuals to become aware of their unhelpful thinking styles and their impact, and to teach them skills for challenging these in order to move towards more balanced and helpful thoughts.

\section{Implications for assessment}

Cognitive-behavioural therapists emphasise unhelpful thinking styles because they recognise a link between the view individuals take of a situation and the impact that this has on how they feel emotionally and physically, and on the altered 
behaviours that result. Because this article aims to describe a generic model, the examples we give address two of the most common psychiatric presentations - anxiety and depression.

\section{What people think can affect how they feel emotionally}

The Five Areas Assessment model summarises the reciprocal links between mood state (e.g. anxiety or depression) and altered thinking. Thus, adverse changes in mood are associated with extreme and unhelpful thoughts (i.e. thoughts that are more negative or catastrophic). For example, if an individual experiences thoughts that other people do not like him, or perceives himself to be inferior to others, or sees the future as bleak and constantly predicts that everything he does is bound to go wrong, he is likely to feel more anxious and/or depressed. Similarly, if mood changes for the worse then thinking is likely to become more extreme and unhelpful. In this way a reciprocal relationship is established between extreme thinking and altered mood.

\section{Example}

A common clinical example that illustrates this point is seen in patients who have experienced traumatic upset and have subsequently developed depression. As the depression becomes prominent, they begin to notice more intrusive and upsetting memories of what happened, which further adds to their emotional distress. Here, the extreme and unhelpful thoughts act to keep the depression going. As the depression responds to treatment, the intrusive memories often reduce and the individuals are less bothered by them.

This reciprocal relationship can be identified by looking at a specific time when mood has worsened and then asking a series of questions such as:

'When you were in the pub with your friends at what point did you feel most anxious?'

'How anxious did you feel at that time on a scale of 0 to 100 , where 0 is feeling no anxiety at all and 100 is the most anxious you have ever felt?'

'At that moment when you came back from the toilet and your friends were all laughing and you felt 95\% anxious, what was going through your mind?'

'When you noticed the thought "They think I'm an idiot and will end up rejecting me", how much did you believe it at the time, on the same 0 to 100 scale?'

'Is it possible that that thought and how anxious you felt are linked?'

The aim of this series of questions is to identify and rate the belief in an extreme and unhelpful thought, and at the same time teach the individual skills in recognising the links between his thoughts and feelings.

\section{What people think can affect what they do}

Extreme thoughts may lead individuals to reduce or stop doing activities that previously gave them a sense of pleasure or achievement, or to start doing things that actually worsen how they feel. This establishes a reciprocal relationship between extreme thinking and reduced/avoided activities or unhelpful behaviours.

\section{Example \\ The effect of reducing activities is often to reduce doing things that would have provided a sense of pleasure or achievement, thus adding to depression. Similarly, in anxiety individuals may avoid anxiety- provoking situations. They may also try to block adverse emotional states such as fear, anxiety, shame, anger or depression by using unhelpful behaviours such as drinking (these three responses are the focus of the next article in this series, by Fox et al, 2002). The resulting patterns of behaviour have an unhelpful impact on how individuals feel, by causing adverse physical, psychological and social consequences in the short or longer term. The altered behaviour again acts to keep the depression or anxiety going. \\ These links between thoughts and behaviours can be identified by asking questions such as: 'When you noticed the thought "They think I'm an idiot and will end up rejecting me", which you believed $95 \%$, did that have any influence on what you did as a result? Is it possible that the thought and the fact that you suddenly left the pub are linked here?' \\ Interaction between the five key areas}

Box 1 gives an example of how situations, thoughts, emotional and physical feelings and altered behaviour link together. These changes may be linked to each of the areas in the Five Areas Assessment model.

The example in Box 1 illustrates that what we think affects how we feel and what we do. It is not situations in themselves that mediate our emotional responses, but our interpretation or view of events. In depression and anxiety, people become overly prone to interpreting very many things in the extreme and unhelpful ways described above. This type of thinking gets outs of proportion and unhelpfully affects people's feelings and actions. As a treatment, CBT aims to identify and improve the unhelpfully altered thinking and behaviours. 


\section{Box 1 How the five key areas interact}

Imagine that you are experiencing a depressive disorder.

Situation As you are walking down a road, someone you know well walks by and doesn't speak to you. Altered thinking You could explain this to yourself in a number of ways. Let us say that you jumped to the very negative conclusion that 'She doesn't like me' and you believed this $80 \%$.

Altered physical feelings You might notice some altered physical symptoms such as feeling low in energy and restless; that evening you may have difficulty sleeping.

Altered emotional feelings This might lead to altered emotions (feeling even lower in mood).

Altered behaviour Your altered physical and emotional feelings may cause you to go home and avoid company. In the longer term you might possibly avoid the person or act differently towards her.

Your extreme and unhelpful thoughts and altered behaviour in this instance may act to keep your depression going: your avoidance of this friend in future will prevent you from recognising that your interpretation of her behaviour was both unhelpful and untrue. Your actions end up reducing your confidence still further and maintaining your depression.

But you may have misinterpreted your friend's behaviour:

Situation As you are walking down a road, someone you know well walks by and doesn't say anything to you. You happen to know that she has just received some bad news.

Altered thinking You might then have thought, 'She was upset and preoccupied and just didn't see me' and believed this $100 \%$.

Altered physical feelings You might therefore not have experienced any significant physical changes. Altered emotional feelings You might have felt empathy for her.

Altered behaviour You might have gone out of your way to talk to her.

\section{How common are the unhelpful thinking styles?}

\section{Experiment}

Consider the following three situations. Read each statement as if it were happening to you right now and write down the immediate thoughts that pop into your mind. Then examine each thought and identify the unhelpful thinking styles outlined in Table 1 that are characteristic of these thoughts.

1 You have gone into town to meet your friend at $10.00 \mathrm{am}$, but he does not turn up.

2 You are giving a talk at a management meeting and you notice someone in the audience yawning.

3 You go to do some last-minute photocopying for a presentation for a job interview. The machine jams halfway through. It needs the engineer.

In large group-teaching sessions of health care practitioners, when asking attendees how many of the unhelpful thinking styles they have noticed in themselves (the task completed in the above experiment), the median is always 3 or 4 . Fewer people show 5 or 6 , or only 1 or 2 of these styles. This illustrates that unhelpful styles of thinking occur in all of us from time to time. A key difference during times of mental disorder is that these thoughts become more frequent and more intrusive (i.e. they have a higher frequency and duration) and become harder to dismiss (i.e. they are believed more). As a result, extreme and unhelpful thinking becomes part of the problem, by acting to keep the person feeling distressed, and/or acting in ways that add to and maintain the problems. Identifying recurrent patterns of unhelpful thinking styles provides targets for change that can improve how the person feels.

It should be noted that the CBT approach does not argue that depression or anxiety are directly caused by extreme and unhelpful thinking. Rather, it argues that such thinking is present during times of depression and/or anxiety. Such thinking is therefore most usefully formulated as a symptom of depression and anxiety. Since the five areas described in the model are interdependent, intervening in any one of these domains should be sufficient to lead to improvement in the remaining domains. Identifying and modifying extreme and unhelpful thinking can therefore be an effective intervention and may be combined with other interventions, such as planning a step-by-step increase in activity (the altered behaviour domain) or taking antidepressant medication (the altered physical symptoms domain).

A couple of rules of thumb are as follows:

- typically, one or two unhelpful thinking styles predominate and occur repeatedly;

- the crucial thing is to help patients to understand the relationship between altered thinking, altered feelings (both emotional and physical) and altered behaviour and the role this plays in maintaining current problems. 
Table 1 Identifying unhelpful thinking styles (from Williams, 2001)
Unhelpful thinking style
Typical extreme and unhelpful thoughts
Bias against myself
I overlook my strengths
I focus on my weaknesses
I downplay my achievements
I am my own worst critic
Putting a negative slant on things
I see things through dark-tinted glasses
(negative mental filter)
I tend to focus on the negative in situations
Having a gloomy view of the future
I make negative predictions about the future
(making negative predictions/jumping to the worst conclusion: catastrophising)
Negative view about how others see me (mind-reading)
I predict that things will go wrong
Bearing all responsibility
Making extreme statements/rules
I mind-read what others think of me
I often think that others don't like me
I often take things to heart
I take the blame if things go wrong
I take unfair responsibility for things that are not my fault
I often use the words 'always' and 'never' to summarise things
I make 'must', 'should' or 'ought' statements to myself
I use the word 'typical' a lot to describe things that go wrong

\section{Consequences for assessment}

When first starting out assessing patients using the Five Areas Assessment model, most clinicians find that it is the altered thinking box that presents the most difficulty. This may be because in psychiatry, the traditional training has emphasised the importance of the form of symptoms over content and/or cognitive processes. In the CBT approach, content and/or cognitive processes are seen as being as, or even more, important than the exact form of psychopathology present when summarising the range of problems facing an individual. The form of symptoms is still assessed, as this is needed for effective diagnosis.

During assessment, a formal checklist of unhelpful thinking styles (such as that in Table 1) can be used. You can ask your patient a general question such as, 'Have you noticed yourself using any of these thinking styles over the past week?' By working through the checklist with you, the patient can begin the process of learning to identify the unhelpful thinking styles that are most problematic.

The three examples you considered earlier (being stood up, the person yawning during your talk and the photocopier jamming) were carefully chosen to evoke an emotional response. Whenever a strong adverse emotional response occurs, an extreme and unhelpful thought is likely to be present. This phenomenon can be used clinically in two ways.

First, observe the patient for obvious changes in mood as you talk at interview. For example, if she suddenly becomes upset, angry or anxious, rather than moving her away from the topic, instead ask:
'How are you feeling right now?' 'How strongly would you rate that feeling, on a scale of 0 to 100 ?' 'What's going through your mind right now?' and 'How much do you believe that, on a scale of 0 to $100 \%$ ?'

Second, ask the patient to consider in detail specific times when she has felt worse and then go through what happened in great detail, examining each of the five areas. This process is called a thought investigation, and its purpose is to identify problematic extreme and unhelpful thoughts.

\section{Completing a thought investigation}

Because mood and thoughts are linked, investigating the thoughts that are present at a time when the patient feels worse is a helpful way of identifying extreme and unhelpful thoughts. Choose a specific situation during the past week or two when the patient experienced a strong emotional reaction (anger, guilt, anxiety or depression). Encourage the patient to recall the event in great detail, in the first person, present tense as if he were back in that situation. Chosing a fairly recent situation ensures that he has a good memory of what happened. The five areas are then gone through in detail as follows.

\section{Situation when mood altered}

Obtain a clear description of:

- the time: 'What time of day is it?'

- the place: 'Where are you?' 
Box 2 Questions for identifying extreme and unhelpful thoughts

'How do you see yourself?'

'How do others see you?'

'What is happening now - what are the current events/situation?'

'What might happen in the future?'

'How do you see your own body/behaviour/ performance?'

'How do you compare yourself to others?'

'What are you doing well/badly at present?'

'How are you coping compared with how you usually cope?'

'What is so upsetting about this situation?'

'What is the worst thing you could imagine happening?'

'What does this say about you as a person/ professional/parent/partner?'

- the people: 'Who is present. Who are you with?'

- the events: 'What has been said/What events happened?'

\section{Emotional and physical changes that occurred}

Define the range of emotional reactions (depression, anxiety, anger, guilt, shame) in the given situation and rate the intensity of each emotion at the time the situation occurred. This can be achieved using a 0 100 Likert scale.

Note down any strong physical sensations that the patient noticed at that time. These may include symptoms of somatic arousal in anxiety or anger (such as a rapid heart, feeling sweaty or clammy ) or of depression (such as fatigue, pain or a deflated feeling). Remember that these are the symptoms present at the time the patient felt worst and they may not be the same as the longer-term biological/ somatic/endogenous symptoms of a particular psychiatric disorder such as depression.

\section{Thoughts that were present at the time}

This important step helps patients to identify the extreme and unhelpful thoughts associated with each emotional response. It is most useful to focus on emotions that the patient has rated between 60 and 100, as these are likely to be driving the most upsetting thoughts (sometimes referred to as hot thoughts' because they are the most emotionally charged). If the patient is describing events that occurred over several hours or even days, try to focus the task by asking, 'At what point in the situation was your anxiety/anger/guilt greatest?' Remember that thoughts can include words, memories of the past, comments on the present, predictions about the future and also images in the mind's eye.

Asking specific questions such as those in Box 2 can identify extreme and unhelpful thoughts. When specific thoughts have been identified, ask the patient to rate on a scale of $0-100 \%$ how much she believed each one at the time she was distressed. Remind her that the rating should describe how she felt at that time, rather than how she now see things in the relative safety of the clinician's office. This will enable you both to construct a realistic account of the interrelationship between her thoughts, feelings and behaviour during problem situations.

\section{Unhelpful thinking styles that were present}

Next, identify the type of unhelpful thinking styles, using the checklist in Table 1.

\section{Impact of the extreme thoughts on what the patient feels and does}

To make clear the unhelpful effect of such thoughts on the patient's feelings and actions, encourage her to consider in detail the impact on herself, her view of others, how she felt, what she said and what she did.

Try to identify any reduced activity or unhelpful behaviours. Overall, was the impact of the extreme thoughts helpful or unhelpful?

\section{The problem of 'I feel'}

A particular difficulty in identifying extreme and unhelpful thoughts may occur in attempting to distinguish thoughts from feelings. This is not helped by the confusion that exists in the English language, where often no distinction is made between how we report thoughts and how we report feelings. For example, 'I feel sad' is clearly an emotion, but 'I feel that you don't like me' is clearly a thought. However, what about statements such as 'I feel a failure', 'I feel useless' or 'I feel suicidal?' Differentiating thoughts and feelings is more than just a theoretical or academic exercise, because in CBT quite different interventions are offered depending on whether the symptom is a thought, feeling or behaviour. In order for CBT strategies to be effective this lack of clarity needs to be managed. A useful tip is that if the word 'that' or phrase 'that $I^{\prime} m$ a' can be inserted into a statement, then it is more likely to represent a thought. Thus, for example, 'I feel a failure' becomes 'I feel that I'm a failure'.

Another common difficulty is that sometimes individuals find it difficult to identify thoughts. This may be because the thoughts themselves or the action of sharing them with someone else are seen 
as frightening, so the person avoids reporting them. For others it can be quite difficult to identify their mood states clearly because they lack a well-defined language of emotion. This most often occurs in patients who somatise, and the challenge here is to introduce a language of emotion into the discussion. Initially, it may be necessary to use other terms such as frustration and demoralisation and slowly to introduce a language of emotion during subsequent sessions (e.g. 'You seem to look quite tense').

Remember that thoughts can include memories of the past, comments on the present, predictions about the future and also images/mental pictures.

\section{Images/mental pictures in anxiety and depression}

Some people (although not everyone) notice pictures or images in their minds when they feel very anxious and/or depressed (Wegner et al, 1987; Borkovec \& Inz, 1990). Images are a form of thought and like other thoughts can be gloomy, negative or scary. They may occur as still images (like photographs), or seem to be moving (like a video). They may be in black and white or colour. Patients may see themselves from an observer's perspective in a situation (e.g. fainting) or from their own perspective, as if looking through their own eyes at what is happening (e.g. seeing the face of the attacker who is pinning them down). Images may include pictures of themselves collapsing, having a stroke or heart attack, 'going mad', being ridiculed or humiliated, or losing control in front of others. As with all such thoughts, these images add to feelings of fear and/or depression and may lead patients to unhelpfully alter what they do; for example, in times of panic they may suddenly stop what they are doing and hurry away.

\section{Using a thought investigation worksheet}

The thought investigation worksheet has been designed to guide you and your patients in the skill of identifying extreme and unhelpful thoughts, and it summarises the process we have just considered on a single sheet. It uses the Five Areas Assessment structure to identify which extreme and unhelpful thoughts were present at the time the patient felt worst. It uses the CBT approach of asking questions to help patients to identify and then consider the impact of immediate thoughts on how they felt and what they did. The worksheet is designed to allow clinicians to teach patients its use during sessions, as well as enabling them to work through it at home on their own. Worksheets can be used as a template to apply to any problematic situations, breaking each situation down into manageable components that can be considered using a step-wise approach.

Case example: Five Areas Assessment of a panic attack (after Williams et al, 2002, with permission)

Mark is a 25-year-old man who has been experiencing panic attacks for the past 3 months. When he goes shopping to a large supermarket he begins to feel anxious, noticing in particular that he feels hot, sweaty and dizzy. These reactions culminate in a full-blown panic attack with accompanying hyperventilation. Consequently, he has begun to avoid going to large shops. He now goes only to smaller local shops, and only when he knows that they will be quiet.

Mark's thought investigation worksheet in shown in Table 2. As you read through what he has identified, remember that the purpose is for him to carry out a Five Areas Assessment of what happened at the specific time when his mood altered. It is not aiming to summarise the full range of his problems over several days or weeks. Instead, it says what happened to him at 11.00 am on Monday, when he was by himself in the crowded shop buying some bread.

Mark identifies his most upsetting thought (his hot thought) while in the supermarket as 'I'll faint', and at the time he believed this $95 \%$. Contained within this thought are several unhelpful thinking styles. Importantly, Mark has identified an extreme thought (one that shows one of the unhelpful thinking styles in column 4) and an unhelpful thought (column 5). It is these extreme and unhelpful thoughts that are the targets for change.

\section{Practising using the thought investigation worksheet effectively}

You are likely to become more confident in using the worksheet if you practice using it on yourself to begin with. Try to complete it yourself on at least five occasions when you notice your mood altering. At first, you - like your patients - may find it quite difficult to notice your extreme and unhelpful thoughts. The best way of becoming aware of them is to try to notice times when your mood unhelpfully alters (e.g. when you feel upset) and to ask yourself what is going through your mind right now.

When completing the worksheet, answer the questions in sequence, working across from columns 1 to 5 . Try to slow down how quickly you answer each question so that you are as accurate as you can be in the thought investigation. Stop, think and reflect as you consider the five different areas that can be affected when your mood alters. It can be tempting sometimes to skim-read the questions: try not to do this, because the questions have been carefully sequenced to help you to find out more 
Table 2 Mark's thought investigation worksheet identifying extreme and unhelpful thinking during a panic attack

\begin{tabular}{|c|c|c|c|c|}
\hline $\begin{array}{l}1 \text { Situation, relationship or practical } \\
\text { problem when your mood } \\
\text { unhelpfully altered }\end{array}$ & $\begin{array}{l}2 \text { Altered emotional and } \\
\text { physical feelings }\end{array}$ & $\begin{array}{l}3 \text { What immediate thoughts did you } \\
\text { have at the time? }\end{array}$ & $\begin{array}{l}4 \text { What unhelpful thinking } \\
\text { style(s) occurred? }\end{array}$ & $\begin{array}{l}5 \text { What was the impact of the } \\
\text { immediate thoughts? }\end{array}$ \\
\hline $\begin{array}{l}\text { Think in detail: Where am I? } \\
\text { What am I doing? } \\
\text { Consider: } \\
\text { Time: What time of day is it? } \\
\text { Place: Where am I? } \\
\text { People: Who is present? } \\
\text { Who am I with? } \\
\text { Events: What has been said? } \\
\text { What events happened? }\end{array}$ & $\begin{array}{l}\text { Am I: low or sad; guilty; anxious, } \\
\text { tense or panicky; angry or } \\
\text { irritable; ashamed? } \\
\text { State the feelings clearly: } \\
\text { (a) Try to be as precise as possible. } \\
\text { If more than one feeling occurs, } \\
\text { underline the most powerful one. } \\
\text { (b) How powerful (0-100\%) is } \\
\text { this feeling? } \\
\text { (c) Note down any strong physical } \\
\text { sensations you notice. }\end{array}$ & $\begin{array}{l}\text { What is going through my mind? } \\
\text { How do I see: myself; how others see me; } \\
\text { the current situation or events; what might } \\
\text { happen in the future; my own body, } \\
\text { behaviour or performance? } \\
\text { Do I have any memories/images? } \\
\text { (a) State the thought(s) clearly and } \\
\text { precisely. If more than one thought occurs, } \\
\text { underline the most powerful. } \\
\text { (b) Rate (0-100) how strongly you felt the } \\
\text { most powerful thought at the time. }\end{array}$ & $\begin{array}{l}1 \text { Bias against myself. } \\
2 \text { Putting a negative slant on things } \\
\text { (negative mental filter). } \\
3 \text { Having a gloomy view of the future, } \\
\text { jumping to the worst conclusion. } \\
4 \text { Negative view of how others see me. } \\
5 \text { Bearing all responsibility. } \\
6 \text { Making extreme statements or rules } \\
\text { (must, should, ought, always, never). } \\
\text { If any of these styles is present, you } \\
\text { have identified an extreme thought. }\end{array}$ & $\begin{array}{l}\text { (a) What did I do differently? } \\
\text { Consider any: reduced activity and } \\
\text { unhelpful behaviours. } \\
\text { (b) What was the impact on: myself; my } \\
\text { view of others; how I felt; what I said; } \\
\text { what I did. } \\
\text { Overall, was the impact helpful or } \\
\text { unhelpful? } \\
\text { If there is an unhelpful impact, you have } \\
\text { identified an unhelpful thought. }\end{array}$ \\
\hline $\begin{array}{l}\text { Situation: } \\
\text { M onday at } 11.00 \text { am By } \\
\text { myseff, going to local shop to } \\
\text { buy bread. Shop crowded. }\end{array}$ & $\begin{array}{l}\text { (a) very anxious and panicky. } \\
\text { (b) } 85 \% \text { panidky } \\
\text { (c) hot and sweety, over breathing, } \\
\text { rapid heart, dry mouth, blurred } \\
\text { vision, dizzy }\end{array}$ & $\begin{array}{l}\text { (a) I mmediatethought: I'Il faint. } \\
\text { I mages of myseff on the floor, passed } \\
\text { out/unconscious. Everyonewill belooking } \\
\text { at meand thinking that I 'ma fool. } \\
\text { (b) } 95 \%\end{array}$ & $\begin{array}{l}\text { Thinkings styles } 1,3 \text { and } 4 \text { are } \\
\text { present }\end{array}$ & $\begin{array}{l}\text { (a) Avoidance- dropped the basket and ran } \\
\text { out of theshop. Avoiding largeshops.Only } \\
\text { going to smaller shops at quieter times. } \\
\text { (b) Overall, an unhdpful impact, as it drev } \\
\text { attention to meand reduced my confidence }\end{array}$ \\
\hline
\end{tabular}

(c) Williams et al (2002)

Table 3 Mark's thought challenge worksheet challenging the thought ' $I$ 'll faint'

6 Reasons supporting the immediate thought

List all the reasons why I believed the immediate thought at the time

I was hot and sweety and dizzy. The dizziness mademethink that I woyld collapse I couldn catch my breath. I fett røally physically bad.

I was sure I would collapse

(c) Williams et al (2002)
7 Evidence against the immediate thought

Is there anything to make me think that the thought is incorrect?

Are there any other ways of explaining the situation that are more accurate?

If I wasn't feeling like this, what would I say?

Would I tell a friend who believed the same thought that they were wrong?

What would other people say?

Have others given me different opinions about the thought?

Well, I didn't collapseand I never havecollapsed. That makes collapsing pretty unlikey.

$M$ y doctor says anxidy can It's to do with tension and panic not a physical problem l'd tell a friend ' $Y$ ou an overomethis. Kep working on it with your doctor.'

M y doctor says it's impossible to collapseduring panic M y dodor says it's inpossildetoca lapseduring panic because the heart speeds up, but in a faint it slows down. Minederinty speeds up, sol cant fait. Hesays that to stop overtreathing I should dosemy mouth and breath
8 Come to a balanced conclusion

Use the answers from columns $6 \& 7$ to try to come up with a balanced and helpful conclusion. Look for a conclusion that you can believe. It should be based on all the information available to you Bear in mind the reasons for and against

believing the immediate thought.

I 'm not going to collapse The physical sensations 1. I 'I go back to theshop and usethethought because of this.

I believethis condusion $95 \%$. $\begin{array}{ll}95 \% . & \text { go into theshop, so that I can begin to test out } \\ \text { whether my fers are really true }\end{array}$ 2. I'll stay put if I fed likel did aga 2.1 3. if and takenormal-sice 
about the different changes that occur during anxiety and depression. Finally, write down what you find. This can help you to put what happened into perspective and to discover things about yourself or how you deal with problematic situations of which you were unaware.

\section{Challenging extreme and unhelpful thoughts}

Once patients have repeatedly practised noticing and recording extreme and unhelpful thoughts, they are ready to move on to the next stage - how to challenge these thoughts. To do this, the thought challenge worksheet has been created (Table 3).

\section{Example: Challenging extreme and unhelpful thoughts}

Mark goes on to complete the thought challenge worksheet in order to challenge his thought ' $I$ 'll faint'. Read what he has written in Table 2 and try to link his answers to the questions in Table 3. Completing column 9 ('Plan for putting the balanced conclusion into practice') helps Mark to consider how he can change what he does to reinforce his balanced conclusion and to undermine the hot thought 'I'll faint' by acting against it.

By far the best evidence for or against an extreme and unhelpful thought is found by looking at the consequences of chosing to act or not act on it. Balanced conclusions can be reinforced by acting on them. Recurring extreme and unhelpful thinking patterns can likewise be undermined by acting against them. This is where it is important to have identified exactly what unhelpfully altered behaviours have occurred. In this case, Mark realises that when he is anxious, he has a tendency to leave the shop and avoid going there again.

Mark puts the three points of his plan (summarised in column 9) into action, and finds that although he still feels anxious, this is far less than before. In particular, he was not as dizzy and this helped him to challenge the fear that he would faint. This process of testing out the new balanced conclusion in practice can be helpfully described as carrying out an experiment. The results of this experiment can be reviewed by asking the four questions: 'What went well?' 'What didn't go so well?' ‘What have I learned from what happened?'”How can I put what I have learned into practice?'

\section{How to use the thought challenge worksheet effectively}

The following suggestions will help you to get the most out of completing the thought challenge worksheet with your patients.
Challenge one thought at a time - start with the hot thought identified on the thought investigation worksheet.

Use the questions at the top of each column to guide you and your patient through the process of challenging extreme and unhelpful thoughts. The questions should be read and answered in order.

Encourage the patient to stop, think and reflect before writing down the answers. This process of interacting with the materials and seeing what has been written helps the individual to begin to question their extreme and unhelpful thoughts.

The column that patients are likely to have the least difficulty with is column 6 , where they are asked to identify evidence supporting their extreme and unhelpful thought. People with anxiety and depression are often very good at identifying reasons why things may go wrong.

The column that patients are likely to have the most difficulty with is column 7 , where they are asked to identify evidence against their extreme and unhelpful thought. The questions in this column have been carefully selected as representing particularly effective questions that can help patients challenge their extreme and unhelpful thinking.

If the patient seems very 'stuck' when completing the worksheet, consider the possibility that a core belief (sometimes called a schema in the traditional CBT model) is being challenged. Such thoughts are very much more difficult to challenge and require the use of other additional CBT interventions.

A crucial part of the thought challenge process is putting the balanced conclusion into practice. It is only when new ideas are tested out in everyday life that new learning can occur. This will help patients to make important changes in their life, and avoid the task being a purely intellectual activity. It asks them to test the validity of their extreme and unhelpful thinking and of their new balanced and helpful thoughts. Completing the worksheets and putting into practice what they have learned between sessions is an important part of change (Kazantzis et al, 2000).

\section{Putting into practice what you have learned}

Putting into practice the skills that you have read about will allow you to find out how useful (or not) such an approach may be for you and your patients. Copies of blank Five Areas Assessment and challenge worksheets and other useful clinical materials may be downloaded free of charge from http:/ / www.calipso.co.uk. The worksheets may be 
photocopied and used with patients to provide a summary of the range of difficulties that they face. A more detailed series of patient self-help materials, including longer self-help workbooks for use by patients to identify and then challenge their own extreme and unhelpful thoughts, are included in Williams (2001). This includes a license for unlimited photocopying of materials for use with patients or in clinical training.

\section{References}

Beck, A. T. (1976) Cognitive Therapy and the Emotional Disorders. New York: International Universities Press.

- \& Emery, G. (1985) Anxiety Disorders and Phobias: A Cognitive Perspective. New York: Basic Books.

- - Rush, J. A., Shaw, B. F., et al (1979) Cognitive Therapy of Depression. New York: Guilford Press.

Blackburn, I. M. \& Eunson, K. M. (1989) A content analysis of thoughts and emotions elicited from depressed patients during cognitive therapy. British Journal of Medical Psychology, 62, 23-33.

Borkovec, T. D. \& Inz, J. (1990) The nature of worry in generalised anxiety disorder: a predominance of thought activity. Behaviour Research and Therapy, 28, 153-158.

Clark, D. M. \& Teasdale, J. D. (1982) Diurnal variation in clinical depression and accessibility of memories of positive and negative experiences. Journal of Abnormal Psychology, 91, 87-95.

Dalgleish, T. \& Watts, F. N. (1990) Biases of attention and memory in disorders of anxiety and depression. Clinical Psychology Review, 10, 589-604.

Garland, A., Fox, R. \& Williams, C. (2002) Overcoming reduced activity and avoidance: a Five Areas approach Advances in Psychiatric Treatment, 8, in press.

Gilbert, P. (1998) What is shame? Some core issues and controversies. In Shame: Interpersonal Behaviour, Psychopathology and Culture (eds P. Gilbert \& B. Andrews), pp. 3-38. Oxford: Oxford University Press.

Hagga, D. A., Dyck, M. J. \& Ernst, D. (1991) Empirical status of cognitive theory of depression. Psychological Bulletin, 110, 215-236.

Kazantzis, N., Deane, F. P. \& Ronan, K. R. (2000) Homework assignments in cognitive and behavioural therapy: a metaanalysis. Clinical Psychology: Science and Practice, 7, 189202.

Mathews, A. M. \& MacLeod, C. (1986) Discrimination of threat cues without awareness in anxiety states. Journal of Abnormal Psychology, 95, 236-240.

Nezu, A. M., Nezu, C. M., \& Perri, M. G. (1989) ProblemSolving Therapy for Depression. New York: John Wiley \& Sons.

Wegner, D. M., Schneider, D. J., Carter, S. R. III, et al (1987) Paradoxical effects of thought suppression. Journal of Personality and Social Psychology, 53, 5-13.

Williams, C J. (2001) Overcoming Depression: A Five Areas Approach. London: Arnold.

- \& Garland, A. (2002) A cognitive-behavioural therapy assessment model for use in everyday clinical practice. Advances in Psychiatric Treatment, 8, 172-179.

-, Richards, P. \& Whitton, I. (2002). I'm Not Supposed to Feel Like This. London: Hodder and Stoughton.

— \& Whitfield, G. (2001) Written and computer-based selfhelp treatments for depression. British Medical Bulletin, 57, 133-144.
Williams, J. M. G. \& Dritschel, B. H. (1988) Emotional disturbance and specificity of autobiographical memory. Cognition and Emotion, 2, 221-234.

Whitfield, G. \& Williams, C. (2002) The evidence base for cognitive-behavioural therapy: a challenge for service delivery. Advances in Psychiatric Treatment, 8, in press.

Wright, B., Williams, C. \& Garland, A. (2002) Using the Five Areas cognitive-behavioural therapy model with psychiatric patients. Advances in Psychiatric Treatment, 8 , 309-317

\section{Multiple choice questions}

1. The following are examples of an unhelpful thinking style:

a it's all my fault that my partner left me

b I should always do my best

c I didn't do anything yesterday

$\mathrm{d}$ passing my driving test wasn't that great - anyone can do that

e I'm not going to go to the party because no one will speak to me.

2. The following are examples of thoughts:
a I feel down
b I feel that I've failed
c I feel angry
d I'm feeling useless today
e I'll mess up the interview.

3. The following are compontents of a thought identification worksheet:

a asking 'What would you tell a friend who believed the same thing?'

b looking in detail at the time and place the patient felt worst

$c$ indentifiying the impact of how the patient felt and what he/she did

$\mathrm{d}$ coming to a balanced conclusion

e rating the patient's belief in their ' ot' $^{\prime}$ thought.

\section{MCQ answers}

$\begin{array}{llll}\text { 1 } & 2 & 3 \\ \text { a } & \text { a } & \text { a } F & \text { a } F \\ \text { b T } & \text { b T } & \text { b T } \\ \text { c T } & \text { c F } & \text { c T } \\ \text { d T } & \text { d T } & \text { d F } \\ \text { e T } & \text { e T } & \text { e T }\end{array}$

